\title{
Evolution of LNAPL contamination plume in fractured aquifers
}

\author{
Simone Mineo ${ }^{1}\left[\right.$ Filippo Maria Luigi Dell'Aera ${ }^{2} \cdot$ Maria Rizzotto $^{3}$
}

Received: 1 August 2021 / Accepted: 19 February 2022 / Published online: 5 March 2022

(c) The Author(s) 2022, corrected publication 2022

\begin{abstract}
The LNAPL contamination affecting an industrial area of southeastern Sicily (Italy) is reported herein as a case study to analyze some peculiarities on its spatial evolution. The free-phase product of light hydrocarbons, leaked from a tank, deserved investigations due to its anomalous migration trend, which was not consistent with the static groundwater flow direction of the area. The collection of geological and hydrogeological data and their organization into a GIS database allowed reconstructing the evolutionary stage of the plume within the 2014-2020 time interval, providing some explanation to the scientific problem. The supernatant thickness was compared with the groundwater oscillation, leading to consideration on the aquifer typology. The causes of the peculiar migration trend were found in three main factors, among which the geological and geostructural ones gain a key relevance. Achieved results show that the rock mass fracturing and the presence of underground structures, probably of tectonic origin, are responsible in driving the contamination plume through a preferential path under the dynamic condition induced by anthropic activities. This supports the need of underground geological and geostructural knowledge when dealing with similar issues and when designing specific remediation measures; the case study presented herein demonstrates that the correct location of remedial measures is crucial for reclamation purposes. Furthermore, data were statistically analyzed looking for a relation between real and apparent supernatant thickness. Prediction equations, for a quick estimation of the contamination entity in such type of aquifers, are presented providing hints for future studies on other settings worldwide.
\end{abstract}

Keywords LNAPL $\cdot$ Plume migration $\cdot$ Rock degree of fracturing $\cdot$ Thickness $\cdot$ Aquifer

\section{Introduction}

Light non-aqueous phase liquid (LNAPL) pollution is known to cause severe contamination issues worldwide (e.g., Hubbard et al. 2001; Dippenaar et al. 2005; Lari et al. 2021). Its underground migration is very complex and several studies are aimed at monitoring its evolution through indirect prospecting or direct borehole inspections (e.g., Cassidy 2007; Guo et al. 2007; Li et al. 2012). Petroleum and its derivatives are the most common LNAPL and its underground contamination represents a recurring problem

Simone Mineo

smineo@unict.it

1 Dipartimento Di Scienze Biologiche, Geologiche E Ambientali, Università Degli Studi Di Catania, Corso Italia 57, Catania, Italy

2 Via Duca degli Abruzzi 273, Catania, Italy

3 ISAB S.R.L, Ex SS 114, Km 146, Priolo Gargallo, Siracusa, Italy in industrialized spots and in oil producing factories. In fact, it can affect the environmental matrixes in the form of either vapor phase in soil pore spaces, or liquid residual LNAPL, or free-phase LNAPL in the water-unsaturated zone, or, finally, as entrapped LNAPL globules above and below the water table (ASTM E2531-06 2014; Azimi et al. 2020). When the LNAPL contamination state of an area reaches relevant levels, it is common to find a thickness of free-phase supernatant product between groundwater and air. In this case, the physical behavior of the LNAPL layer is also controlled by groundwater table fluctuation over time, which affects the subsurface distribution of the different LNAPL phases (Gatsios et al. 2018; Atteia et al. 2019). This represents a key aspect to consider when dealing with a site-specific environmental characterization or remediation. Some literature experiences demonstrated that the LNAPL free-phase thickness in the aquifer is different from the one measured in wells (Ballestero et al. 1994; Steffy et al. 1995; Deska and Ociepa 2013). Furthermore, LNAPL contamination floating over the groundwater table is not static and is 
not subject to gravity, due to the lower density if compared to water, but it rather tends to spread horizontally and its migration is function of the groundwater direction of flow. With particular reference to fractured aquifers, groundwater flows through rock mass fractures (e.g., Pyrak-Nolte et al. 1987) according to their density, orientation, aperture, and persistence. Along its path through the fractures, water transports the LNAPL, which passively follows the same general direction of the groundwater (Mercer and Spalding 1991) traveling even long distances, thus representing a risk to human health. Nevertheless, the heterogeneity of rock masses at different scales strongly conditions the groundwater regime, thus in turn the LNAPL migration. Fractured media, based on the constituent rock type and geological setting, can show a wide variety of characteristics, in terms of porosity and permeability, influencing the hydrogeologic behavior of groundwater and contaminants (ITRC 2018). In particular, rock masses affected by low rock matrix permeability but high secondary porosity (i.e., fracture net) are usually characterized by fluid flow in fractures, and storage in both the rock matrix and fractures (Nelson 2001). In fact, it is known that the fracture net characteristics, such as aperture and intersection, play a key role in controlling fluid flow and solute transport in fractured media, thus determining a different behavior of LNAPL in rock masses if compared to porous media (Hardisty et al. 2003; Ji et al. 2006; Yang et al. 2012). Hardisty et al. (2003) state that site investigation should focus on determination of fracture network and rock matrix properties, as well as on understanding of groundwater surface fluctuation dynamics, and consideration of spatial LNAPL distribution. In this perspective, this paper presents the case study of the evolution of a LNAPL contamination and of its peculiar migration path within a fractured aquifer, with the aims of increasing the scientific casuistry on underground pollution in geostructurally complex areas and of analyzing the main factors affecting the migration of pollutants. The study area is a relevant and known industrial petrochemical pole of southeastern Sicily (Italy), located near Priolo village (Fig. 1). The relevance of such spot arises from the high pollution rates, which allowed including it into the Italian Sites of National Interest for remediation purposes (SIN). In this area, LNAPL contamination plumes originating from a leak in a petrochemical storage tank moved according to a peculiar path, different from the static flow direction of groundwater. This kind of point-source of contamination is common in industrial sites, as highlighted by several case studies worldwide (Chang and Lin 2006; Ching Sheng et al. 2019; Liying and Yibo 2010; Etkin 2009; Fewtrell and Hirst 1998). The structural damages of storage tanks cause the release of light hydrophobic liquids, such as LNAPLs into the subsurface, giving rise to relevant pollution issues, which can remain undiscovered for times.

To monitor the evolution of the contamination plumes studied herein, a rich surveying and monitoring campaign has been carried out over years. Underground data, both geological and hydrogeological, covering the 2014-2020 time interval were organized into a GIS (Geographic Information System) platform and their elaboration allowed carrying out multiple considerations on the presence of a LNAPL plume and its evolution in space and time, even with reference to some geostructural features of the area. Chemical analysis
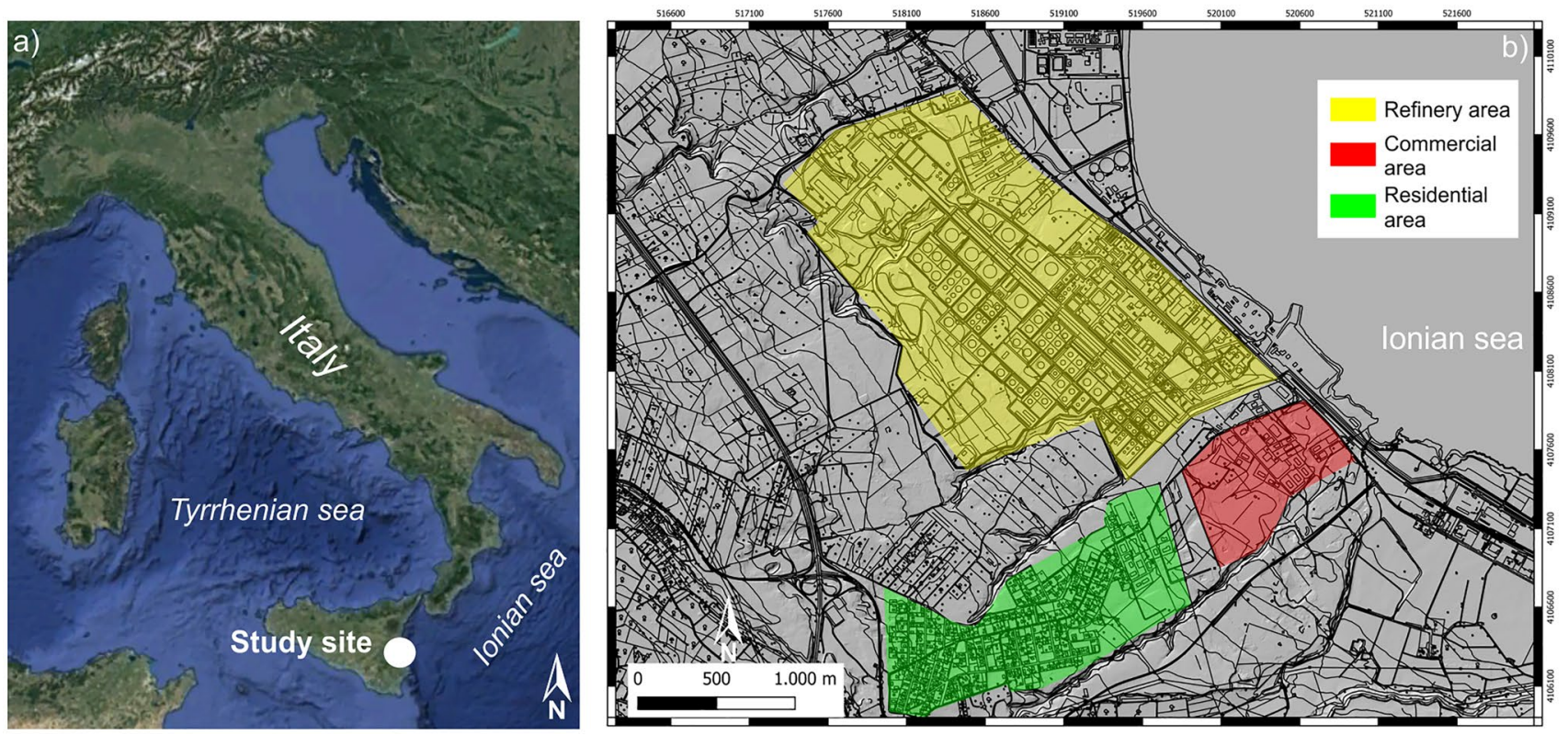

Fig. 1 a) Geographical location of the study site; b) map of the study area with highlighted key areas 
of the free-phase product allowed constraining the age of the leakage thanks to the different compositional product rules that applied in the national territory.

Furthermore, a focus on the LNAPL free-phase thickness is provided herein, with a statistical study on the relation between the air-LNAPL/LNAPL-water interfaces, which allowed carrying out consideration on the aquifer typology and on the relationship between apparent and real supernatant thickness. In fact, it is known that the actual LNAPL thickness in the subsurface is less than the LNAPL thickness in a well (Schwille 1967; van Dam 1967; Lenhard et al. 2017). Therefore, prediction equations were derived from statistical data processing, providing a tool for practical use, as well as hints for further scientific studies.

\section{Methodology}

The methodological approach followed herein started with the collection of geological and hydrogeological data from 630 wells scattered on an about $1.2 \mathrm{~km}^{2}$ area, referred to periodic 6-month survey campaigns covering the 2014-2020 time interval. Data were employed to compile a GIS database holding information on stratigraphy, degree of rock mass fracturing, depth of groundwater table (in static conditions), presence of supernatant and related thickness measured in well (apparent thickness in static condition and real thickness estimated during baildown tests), chemical characterization, and the well geographic coordinates and field setting (Fig. 2). In particular, the chemical supernatant composition was used herein to constrain the age of the leakage, which was even useful to locate the leaking tank and repair it. In the meantime, sided by a field geological survey, the geological setting of the area was defined in terms of both cropping out lithologies and subsoil model.
On the other hand, data on groundwater table were used to study the hydrogeological setting, so to achieve a knowledge on the aquifer behavior in terms of main groundwater static flow direction and fluctuations over time. The LNAPL plume apparent thickness was statistically analyzed starting from punctual data and related static measurements. Contour maps showing the concentration variability of the plume apparent thickness itself were drawn allowing both the mapping of the main plume path and the monitoring of its evolution over time in terms of concentration and efficiency of remedial works. Similarly, the evolution of the dissolved contamination plume was analyzed, according to the availability of data, to shed light on the relation between the two contamination phases. The plume direction was then analyzed and compared to the main groundwater flow direction, highlighting some differences. In order to provide an explanation to the peculiar plume migration path, the results arising from geostructural and geophysical studies, commissioned by the society handling the refinery, were taken into account. In particular, seismic reflection profiles allowed mapping some underground structures, likely related to main discontinuities or faults, whose occurrence was supported by geostructural studies, thus allowing us to provide an explanation for the peculiar plume direction pattern. Furthermore, real and apparent thicknesses of the supernatant product were compared, in order to propose a statistical correlation, which could be useful for prediction purposes.

\section{The studied contamination}

This study refers to a specific contamination case caused by a storage tank leakage in the Priolo refinery area. The contaminating product can be classified as a mixture of light hydrocarbons methyl-t-butyl ether (MTBE) and benzene,
Fig. 2 Conceptual map of the methodological approach and available data

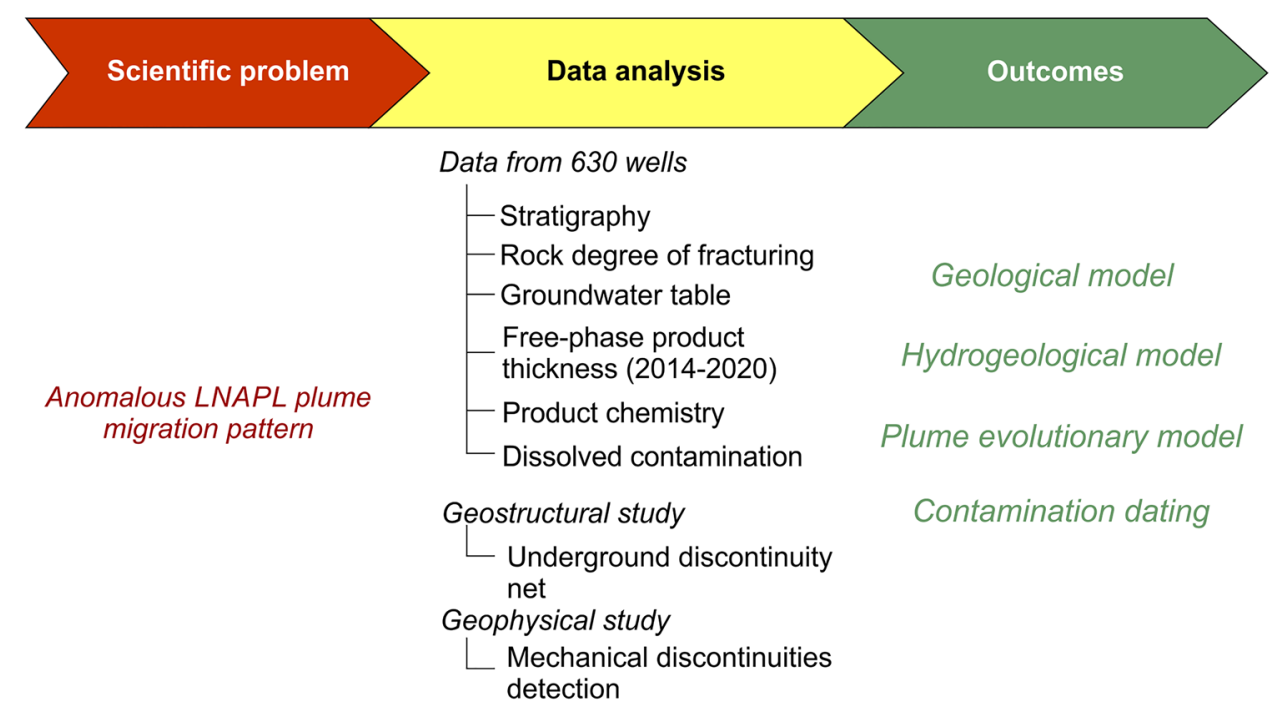


toluene, ethylbenzene, and xylene (BTEX), with a 764.86 $\mathrm{kg} / \mathrm{m}^{3}$ average density. Its vertical migration pattern is likely conditioned by its interaction with the carbonate rock succession crossed during the migration downward. Once the capillary fringe is reached, LNAPL distributed above, at, and below the water table. In fact, the contamination reported herein was analyzed with reference to both the free-phase product and the dissolved rate. In the first case, the supernatant apparent thickness measured in wells allowed mapping the plume distribution and its chemical composition allowed dating the contamination event. In fact, the specific product chemical features (Table 1), given by a sulfur content of 37 ppm, suggest an industrial production period after January 2003. Before that date, an essentially free-sulfur gasoline was produced in Italy. Similarly, based on the aromatics content (on average 45\%), the event likely took place prior to January 2009. In fact, in the time interval 2005-2009, gasoline was produced for the foreign market with a concentration of aromatics greater than $35 \%$. Moreover, from the groundwater chemical analysis, a rate of dissolved contamination was found within the first $25-30 \mathrm{~m}$ of saturated zone.

\section{Geological setting}

From the geological and geodynamic point of view, the study area is located on the carbonate foreland known as Hyblean Plateau, which represents the northernmost portion of the African plate, poorly deformed by the collision with the Eurasian plate in the frame of the Alpine orogenesis (Grasso et al. 1979). Two main structural fault systems cross the area: a NE-SW system and a NW-SE-oriented extensional fault system (Carbone et al. 1982).

The geological formations cropping out in the Hyblean area are mainly Cretaceous-Quaternary carbonates in platform facies, with interbeds of volcanic products emitted during different eruptive phases (Carbone and Lentini 1981) (Fig. 3a). The stratigraphic succession of the study area, defined according to the results of numerous borehole drillings, can be summarized into three main units. Starting from the top to the bottom (Fig. 3b):

- Unit 1: calcarenites and sands of the Panchina Formation (Upper Pleistocene), mainly cropping out in the eastern sector of the study area and unconformably laying on the below calcarenites of the Monti Climiti Formation.

Table 1 Main chemical-physical free-phase product parameters measured during the well monitoring campaigns

\begin{tabular}{lllll}
\hline Density & Sulfur & Aromatics & Olefins & MTBE \\
\hline $764.86 \mathrm{~kg} / \mathrm{m}^{3}$ & $37 \mathrm{ppm}$ & $44.96 \% \mathrm{v} / \mathrm{v}$ & $4.48 \% \mathrm{v} / \mathrm{v}$ & $0.052 \% \mathrm{v} / \mathrm{v}$ \\
\hline
\end{tabular}

- Unit 2: calcarenites and algal-rich limestones belonging to the Oligo-Miocene Monti Climiti Formation (Pedley 1981) unconformably laying on volcanic products.

- Unit 3: Cretaceous submarine volcanites represented by pillow lavas and massive basalts.

This stratigraphy suggests a peculiar geological and geostructural setting, mainly arising from the presence of overlapped carbonate geological layers. It is widely ascertained that carbonate rock masses are affected by chemical dissolution phenomena, leading to the formation of karst features, affecting their geomechanical quality and controlling water flow patterns (e.g., Andriani and Parise 2015; Elshall et al. 2021). Among these, cavities are common in the study area. In fact, a series of Remote Video Inspections, carried out along drilled borehole, confirmed the presence of numerous cavities, sometimes with a well-developed interconnection network (Fig. 3c). More specifically, about $84 \%$ of analyzed wells have at least one cavity. These mostly occur within the unsaturated zone of the aquifer (about $84 \%$ of cavities), with a main concentration and horizontal development at the bedding joints of calcarenites. Such location, above the current groundwater table, is likely related to the tectonic uplift which occurred in the study area from Pleistocene. In fact, the remaining $16 \%$ of detected cavities, likely younger than the above ones, were currently detected by video inspections within the shallow aquifer. Such past tectonic uplift of the area is testified by the presence of orders of marine terraces occurring at the western Hyblean sector (Catalano et al. 2010).

\section{Hydrogeological setting}

Collected well data allowed defining the hydrogeological setting of the area with specific reference to the aquifer structure, water table depth, and main flow direction. The three main stratigraphic units reported in the previous section are also the hydrogeological units involved in the storage and transmission of underground water.

Units 1 and 2 represent the porous medium, characterized by both primary and secondary porosity. While unit 1 (average thickness $0-7 \mathrm{~m}$ ) is characterized by a good rock matrix interconnected porosity and fracturing, favoring the effective infiltration, unit 2 can be classified as a dual-porosity medium. According to Nelson (2001), a dual-porosity type aquifer is characterized by low matrix permeability but high porosity resulting in fluid flow in fractures. In this case, storage occurs in both the rock matrix and fractures and water flow can be locally enhanced by the presence of widespread karst features. According to underground investigations, the heterogeneous degree of fracturing of the rock mass is the main responsible of the wide range of the permeability coefficient $(k)$ estimated by 


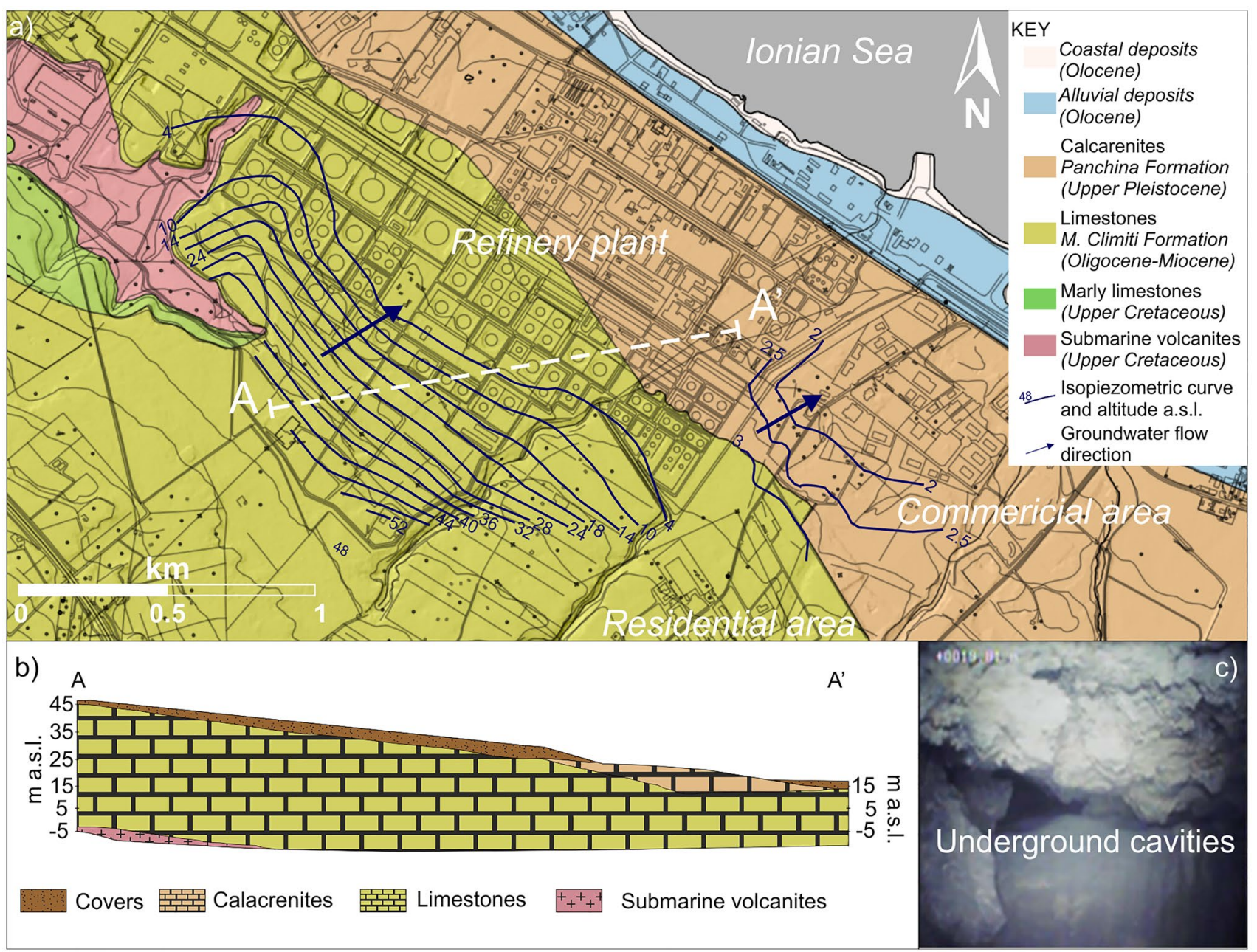

Fig. 3 a) Geological map of the study area with indication of isopiezometric curves (white line indicates the trace of the cross section in inset b); b) schematic geological profile of the study area; c) example of cave surveyed in a borehole

aquifer tests and ranging from $10^{-4}(\mathrm{~m} / \mathrm{s})$, at the most permeable areas, to $10^{-6}(\mathrm{~m} / \mathrm{s})$. Water table lays between 50 and $5 \mathrm{~m}$ a.s.l. (Fig. 3a) and well data, measured in static condition during the 2014-2020 campaigns, show that seasonal fluctuations usually do not exceed $50 \mathrm{~cm}$, testifying a significant recharge contribution from upstream sectors. The main flow direction, estimated according to static well measurements, is oriented towards the coastline (Fig. 3). This datum is consistent with previous literature data (Carbone et al. 1986). Aquiclude is represented by the volcanoclastic products lying below the carbonate succession, characterized by low permeability, and representing a separate aquifer, not affected by the pollution issues analyzed in this research.

\section{Plume monitoring}

Although, according to Fig. 3a, groundwater flows towards northeast in static condition, it must be underlined that most of the time its path is influenced by the pumping activity performed by refinery, farms, and public and private structures for industrial and irrigation purposes. This is a crucial issue because the plume migrates according to the dynamic groundwater flow, showing herein a southeast preferential direction of movement (Fig. 4), relevantly different from the static groundwater flow direction. This occurs for both the free-phase (FP) and the dissolvedphase (DP) plumes. When the contamination monitoring started, in January 2014, the supernatant was found in 22 wells, corresponding to $15 \%$ of wells analyzed herein, with apparent thickness ranging between 4 and $50 \mathrm{~cm}$ (Fig. 4). The FP plume was elongated towards south-east and the highest concentration spot of supernatant product was found at the refinery storage tank area, where the source of pollution used to be. Its front was found as far as the commercial area, with apparent thickness of about $30 \mathrm{~cm}$. In July 2015, supernatant was found in 16 wells, corresponding to $14 \%$ of those surveyed at the time, and the greatest apparent thicknesses (about $60 \mathrm{~cm}$ ) kept affecting 

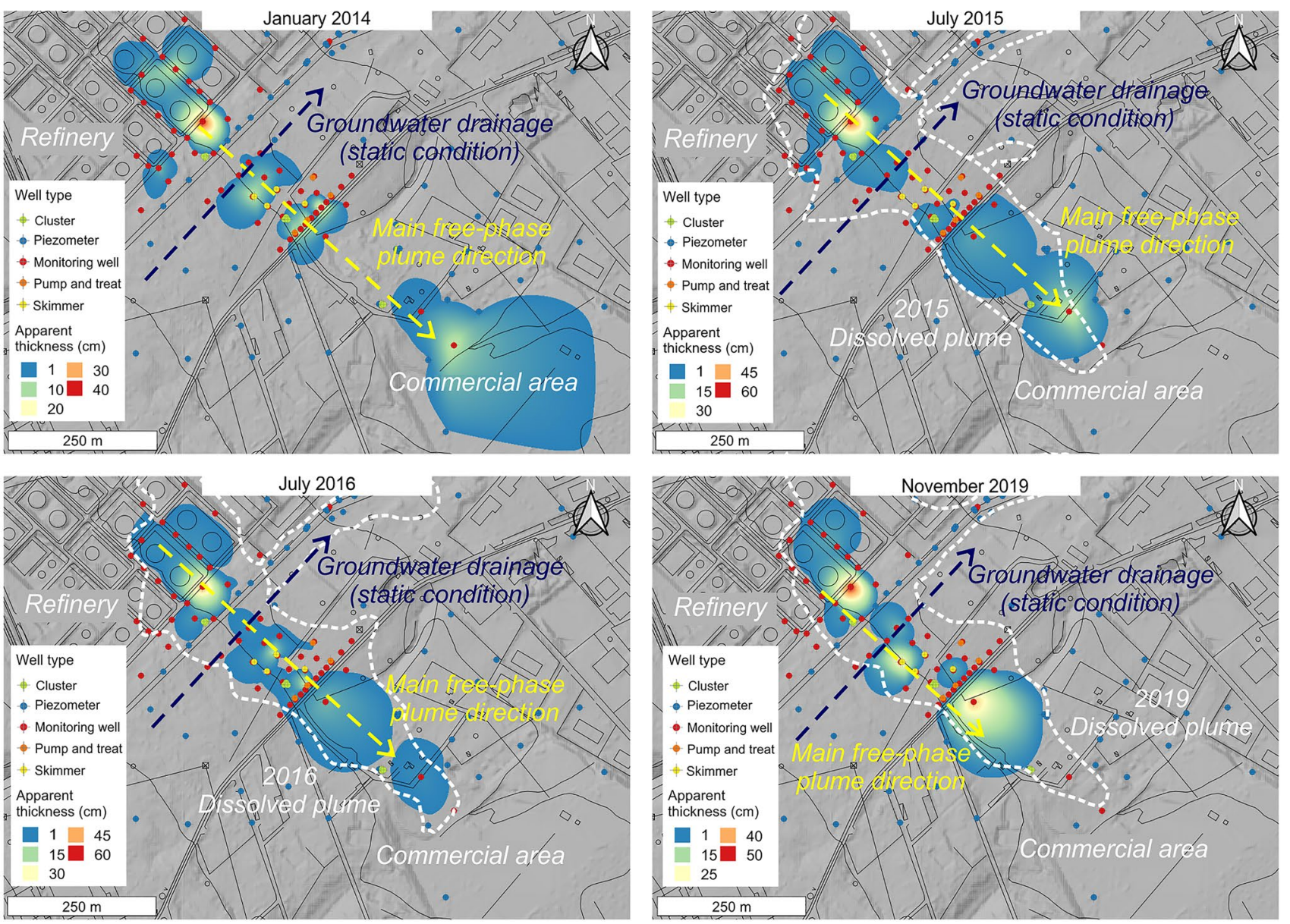

Fig. 4 Comparison between the free-phase product plume apparent thicknesses measured in January 2014, July 2015, July 2016, and November 2019. White dashed lines border the dissolved-phase contamination plume

the refinery tank area (Fig. 4). On the other hand, the PF plume front affected a smaller area, suggesting a kind of positive effect of the containment measures. In fact, in 2012, a pump and treat system was settled in between the commercial area and the refinery plant, in a tentative groundwater remediation activity to prevent the pollution to reach the commercial area. The DP contamination shows a similar migration pattern, with a plume well overlapping to the one belonging to FP. A rate of dissolved contamination was found at some piezometers located at the northeastern sector, probably due to the favorable drainage offered by the high concentration of sampling spot along the natural groundwater flow direction. Nevertheless, such "secondary" DP plume was limited to that area, where no FP contamination was detected.

In July 2016, the number of FP-affected wells raised to 22 , mainly located in the northwestern sector, although the plume concentration kept reducing at the commercial area (Fig. 4). Similarly to the previous year, a good overlapping between FP and DP plumes can be underlined. A relevant improvement of the pollution state was recorded in November 2019, with only 10 wells affected by supernatant presence and a further narrowing of the plume head at the commercial area (Fig. 4). Then, in March 2020, the PF product was found in 6 wells, proving a reduction of polluted measuring spots within the 7-year period considered herein (Fig. 5a), which is reflected also in the reduction of the DP contamination rate. By analyzing in detail such data, it can be noticed that the number of wells affected by FP contamination increases during the summer measuring campaigns along with the supernatant apparent thickness, likely due to the heavier groundwater exploitation. In fact, there is a known relationship between apparent thickness measured in wells and the fluctuation of groundwater level, starting from the assumption that the presence of LNAPL in a well is an indication that the LNAPL adjacent to the well exceeds residual saturation and is mobile. Under unconfined conditions, LNAPL thickness in a monitoring well may increase as the water table falls and LNAPL flows into the well. Contrarywise, when the groundwater table rises, the 
a)

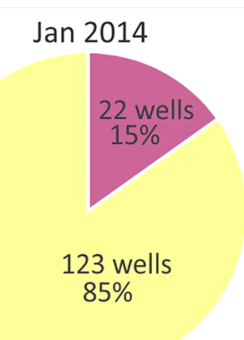

Jul 2015

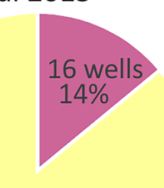

98 wells

$86 \%$
Jul 2016

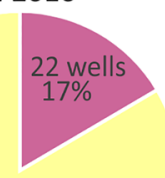

111 wells $83 \%$
Nov 2019

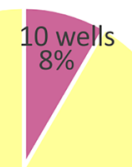

109 wells $92 \%$
Mar 2020

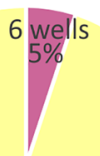

113 wells 95\%

Not affected wells $\square$ Affected wells

b)

b) 40
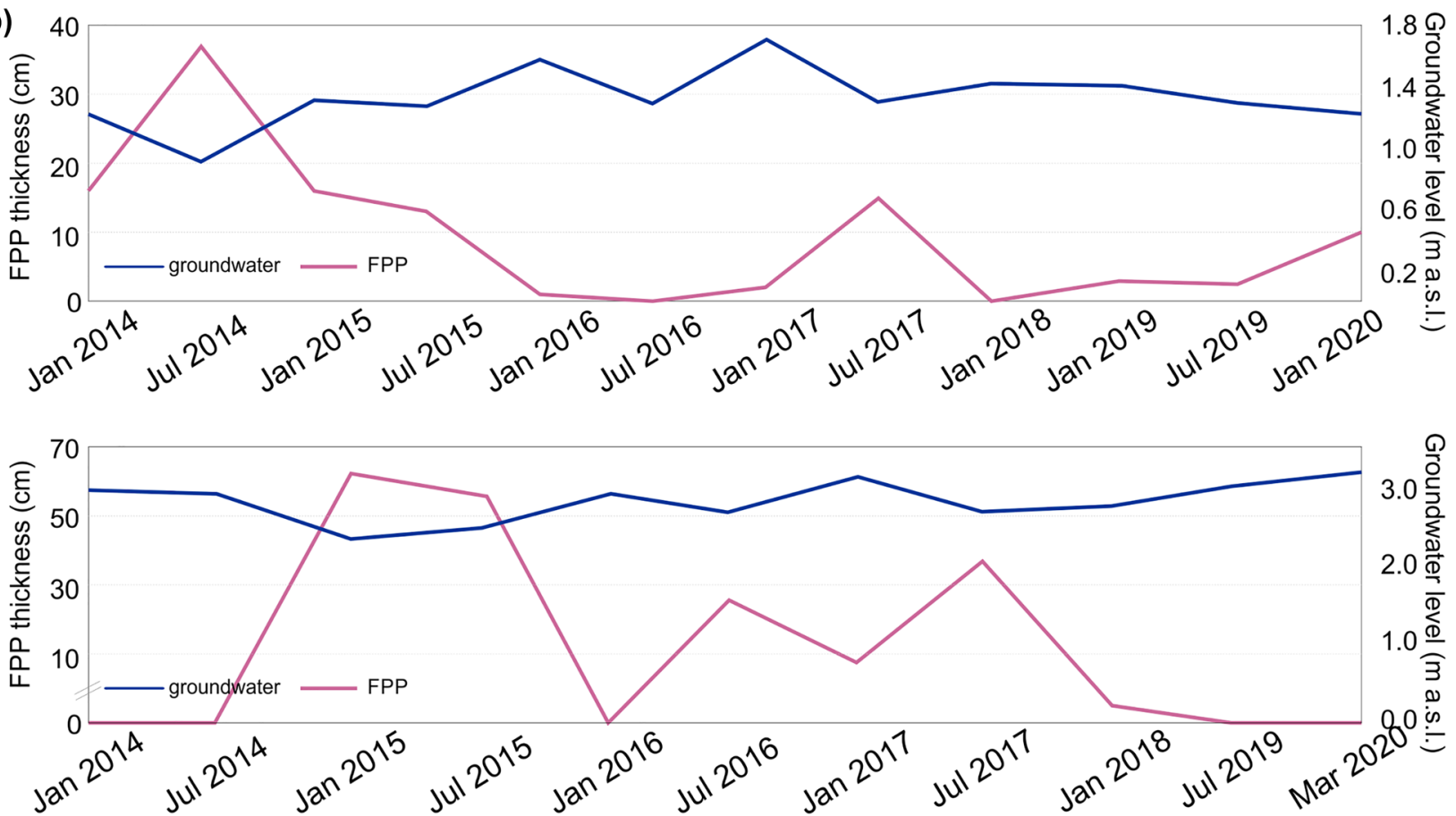

c)

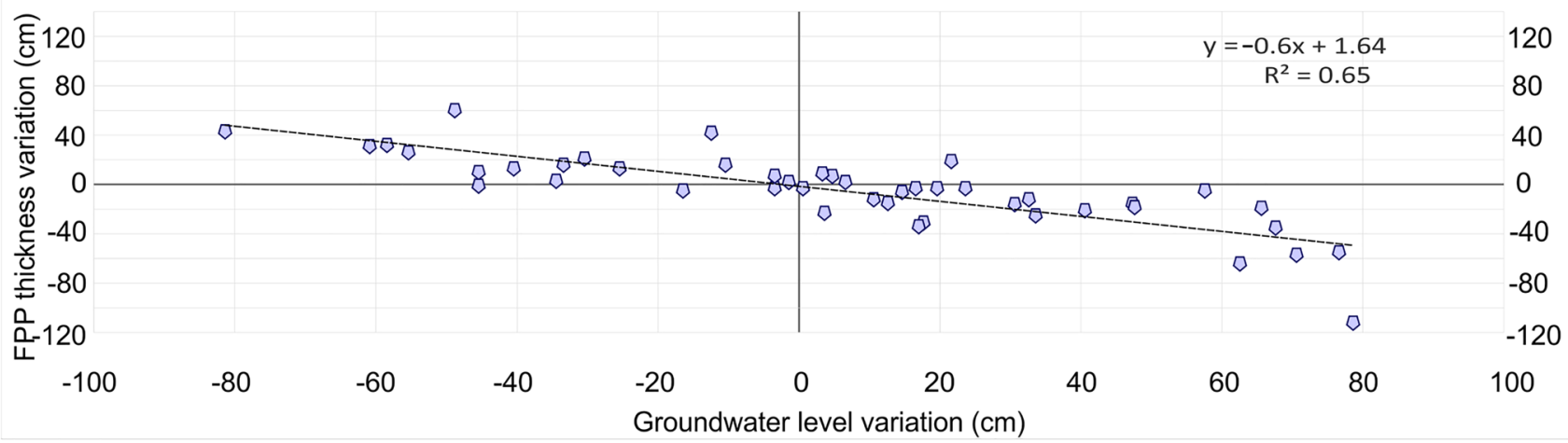

Fig. 5 a) Pie charts showing the number of affected and not affected wells by LNAPL contamination for selected representative measurement campaigns; b) relationship between LNAPL apparent thickness

free-phase product is entrapped in the saturated soil and its apparent thickness in the well decreases (ITRC 2018). The trend reflected by field data shows that free-phase product and groundwater level; c) statistical correlation between the freephase product thickness variation and the entity of groundwater table oscillation measured between two consecutive surveys

thickness generally decreases when the water table rises, index of unconfined aquifer conditions (Fig. 5b). By plotting in a bivariate diagram the values related to groundwater 
table and supernatant thickness variations within two consecutive measurements, with respect to wells located at the plume area, the statistical negative correlation is confirmed (Fig. 5c). This linear trend, with a satisfactory coefficient of determination $\left(r^{2}=0.65\right)$, proves that the entity of groundwater seasonal oscillation is proportionally reflected on the product apparent thickness variation, leading to potential statistical prediction through the resulting Eq. (1).

$F P P t=-0.6 G W v+1.64$

where FPPt is the apparent free-phase thickness variation expressed in centimeters and $G W v$ is the groundwater variation, expressed in centimeters, between two consecutive seasonal measures.

Besides the above considerations, there is a further aspect to take into account, i.e., the plume migration direction. It shows indeed a constant trend towards SE, suggesting the influence of specific factors which should be searched in both the geological setting and the human activity.

\section{Supernatant apparent vs real thickness}

It is widely ascertained that supernatant actual thickness in the subsurface is less than the LNAPL thickness in a well (Schwille 1967; van Dam 1967; Lenhard et al. 2017). This difference arises from the fact that the migration of LNAPL takes place through the capillary fringe, creating a buoyant pool with uniform and constant saturation (Baldi and Pacciani 1997). On the other hand, there is no capillary fringe in monitoring wells, leading to a lower level of water table in the well itself and enhancing the free product flow therein; this produces an exaggerated thickness of supernatant in wells (Hughes et al. 1988; Frollini and Petitta 2018), referred to as apparent thickness. Some literature studies (e.g., de Pastrovich et al. 1979; Ballestero et al. 1994) are focused on such aspect, which can bring significant errors in estimates of drainable LNAPL volume for remediation system design purposes. In this study, although the seasonal plume monitoring was carried out through static sampling of product, the real thickness was locally estimated through baildown tests (Gruszczenski 1987) to have knowledge on the relationship between such two values. Such tests were carried out at selected wells, during different seasonal measuring campaigns over the monitoring time interval considered herein. By plotting on a two-variable diagram the real and apparent thickness values for each considered measurement, a positive linear trend is achieved $\left(r^{2} 0.7\right)$, suggesting a sort of statistical relationship (Fig. 6a). Nevertheless, as above reported, apparent thickness is strongly influenced by groundwater table fluctuations. Therefore, for a more reliable statistical analysis, data were grouped with respect to the seasonal rainfall features of the area by differentiating data measured during spring, when aquifer benefits from a recharging rate arising from rainfalls, and summer-fall, when lowest water table levels are found. The simple correlation analysis returned more satisfactory outcomes, with the best correlation pattern $\left(r^{2} 0.8\right)$ referring to data measured in spring (Fig. 6b). Similarly, thickness values measured in summer-fall are linked by a linear, $r^{2} 0.75$, trend (Fig. 6c). Prediction equations related to such trends are reported below, where $R t$ is the predicted real thickness and $A t$ is the measured apparent thickness.

$R t=0.06 A t-0.42$

$R t=0.034 A t+0.1$

$R t=0.07 A t-0.58$

Such equations can be considered a tentative statistical way to predict real thickness from apparent ones in this type of aquifers. In particular, Eq. (2) results from the general correlation (Fig. 6a), while Eqs. (3) and (4) refer to spring and summer-fall measures, respectively (Fig. 6b, c).

Equations (3) and (4) were employed herein to predict real thickness values starting from the known apparent ones. By plotting achieved predicted values against the corresponding real values measured in wells, a low statistical dispersion around the 1:1 reference line is outlined (Fig. 6d), proving the good statistical reliability of such model.

\section{Factors affecting the plume migration}

The peculiar flow path shown by the analyzed point-source pollutant plumes, both FP and DP, can be ascribed to three main factors: human, geological, and structural. Starting from the human activity, it is well known that pumping procedures can cause changes in the groundwater flow direction (e.g., Walker 2001; Gailey 2017). In the study area, as aforesaid, pumping wells are widespread, with main pumped flow rates at both the refinery and the commercial areas. The specific plume orientation surveyed in the area suggests a sort of preferential drainage towards the commercial area (south-east), where a mall held a pumping system to supply its own services. A secondary migration pattern was detected only for the DP contamination, aligned to the static natural groundwater flow direction, at some piezometers located at the northeastern sector of the area. Nevertheless, the main plume direction is south-east and the reason of such specific trend cannot be explained only by the pumping action, because it alone does not justify the specific directional effect. In fact, other pumping spots are widespread in the area and they apparently did not affect the plume migration. An explanation must be therefore searched in the underground geology, by taking into account the outcomes of the borehole drillings carried out in the area. 


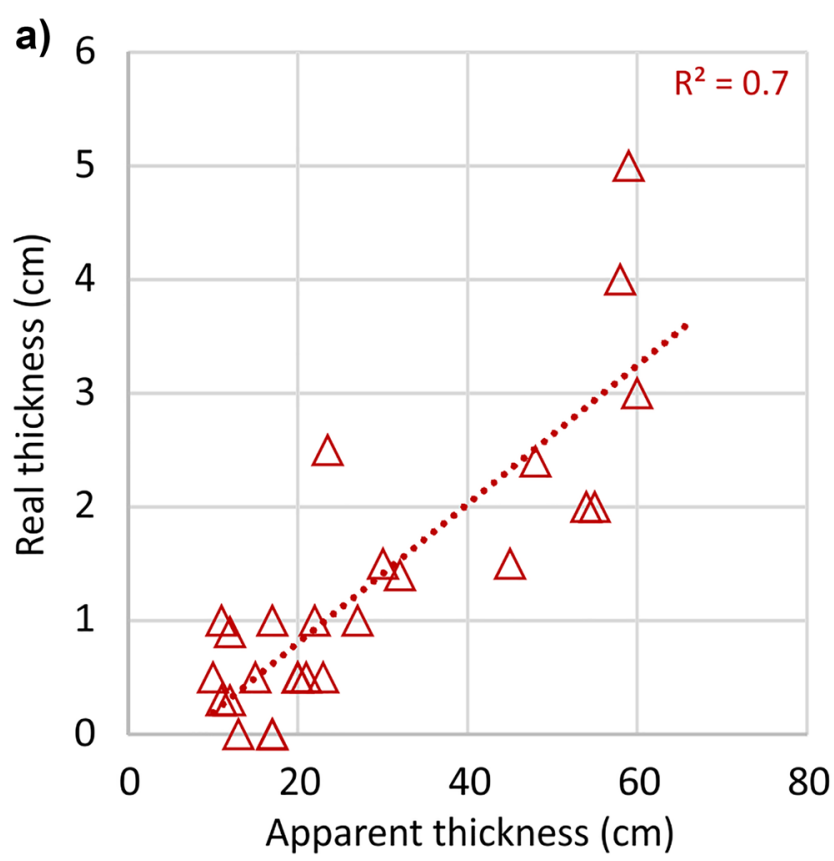

b)
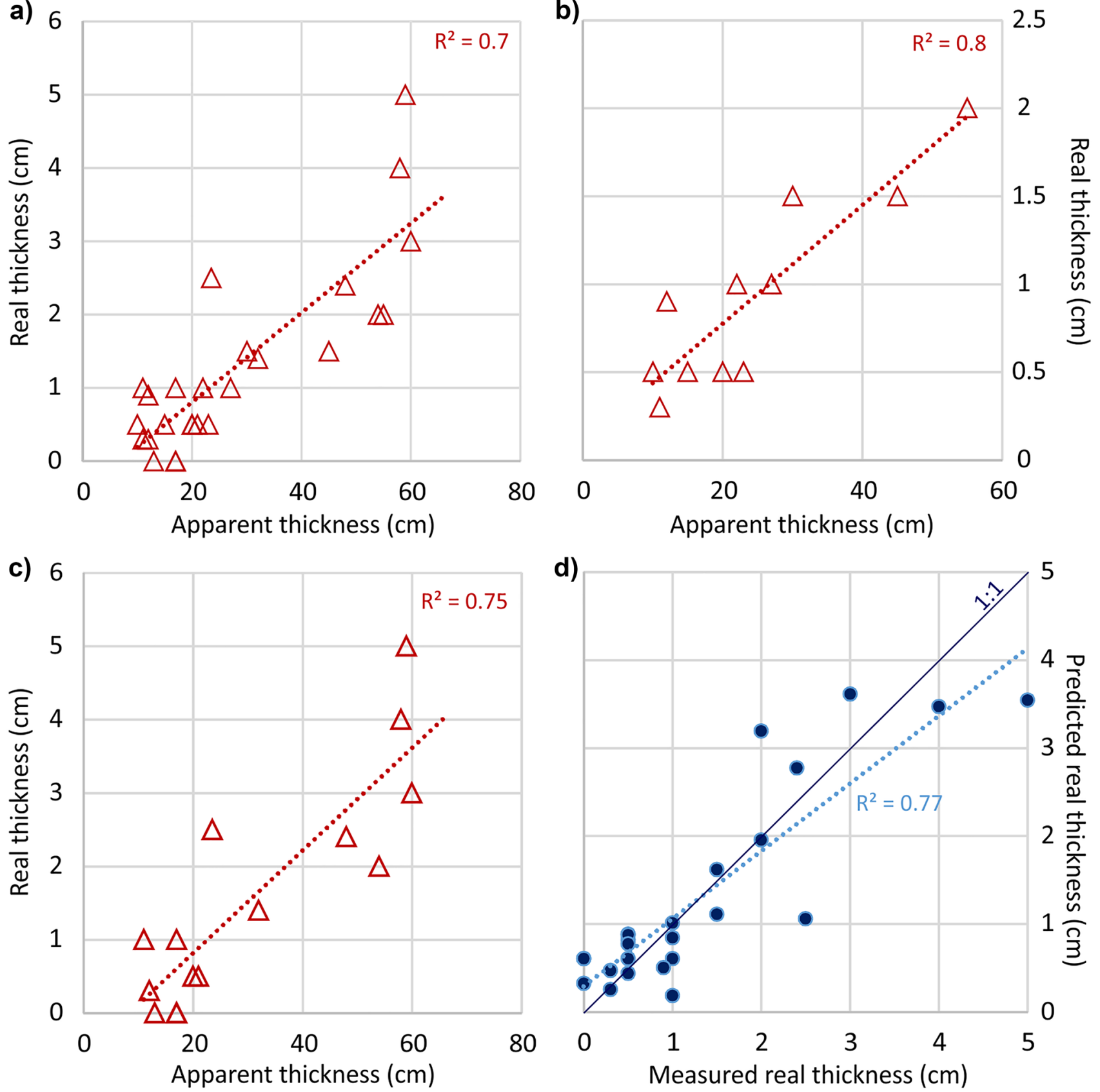

Fig. 6 Statistical correlation between a) real and apparent supernatant thickness measured during the monitoring period with no seasonal distinction; b) real and apparent supernatant thickness measured during the monitoring spring campaigns; c) real and apparent

The analysis of drill cores, matched with the observation of the vertical rock mass succession by video inspections, suggests that about $65-75 \%$ of cracks occurring in the sampled cores originate from detensioning phenomena caused by the drilling action. On the other hand, only $25-35 \%$ of them are related to fractured rock mass portions. This suggests that the potential presence of zones with a higher

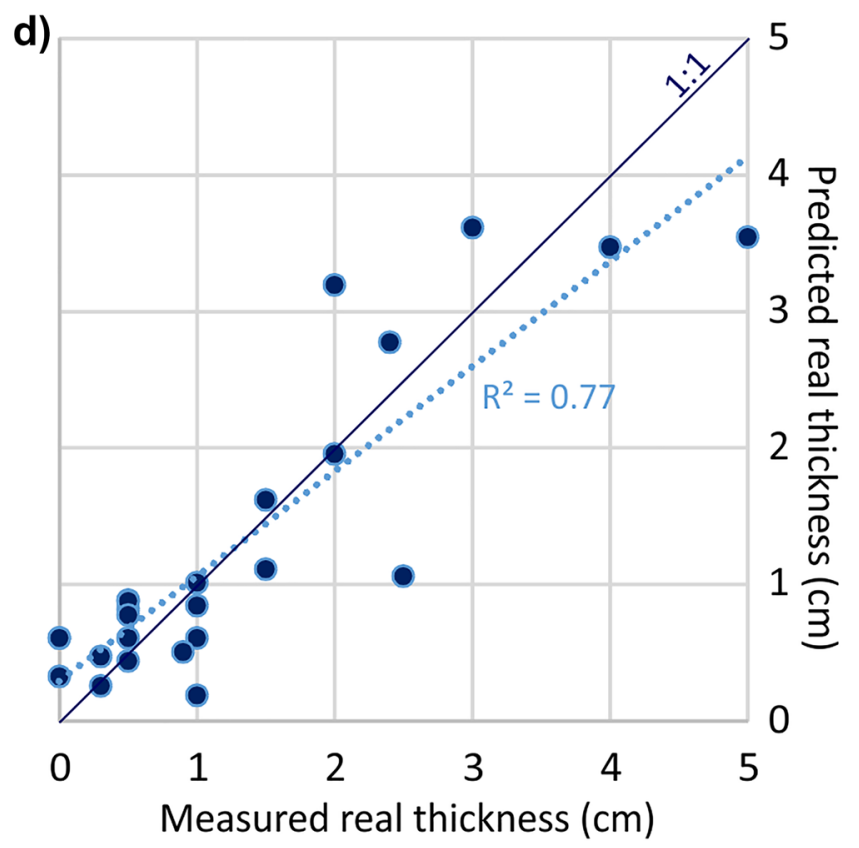

supernatant thickness measured during the monitoring summer-fall campaigns; and d) predicted (Eqs. (3) and (4)) vs measured real supernatant thickness values

concentration of natural fractures would play a key role in the plume migration attitude. To this purpose, the analysis of Rock Quality Designation (RQD; Deere 1963), which is an index directly linked to the degree of rock mass fracturing, was analyzed herein by paying specific attention to the capillary fringe depth. Considering a NW-SE well alignment, RQD measured at the water table depth decreases towards 
SE, suggesting an increasing degree of fracturing of the rock mass (Fig. 7a). This would represent a peculiar geological condition which, together with the presence of karst cavities at the shallowest portions of the saturated zone, enhances the groundwater drawn towards the commercial area thanks to a more favorable drainage. It is indeed known that contaminants can travel long distances through conduit networks in karst environments, sometimes with minimal dispersion if conduit flow dominates (White and White 1989; Elshall et al. 2021; Fryar 2021). To shed further light on this issue, the refinery management commissioned geophysical and geostructural studies over the area, which were carried out in 2013 and 2014, respectively. Seismic reflection profiles (Fig. 7b) show the presence of potential mechanical discontinuities in the subsoil, highlighted by the displacement of some reflectors. This is a key information, suggesting that there might be a further reason enhancing the SW plume migration.

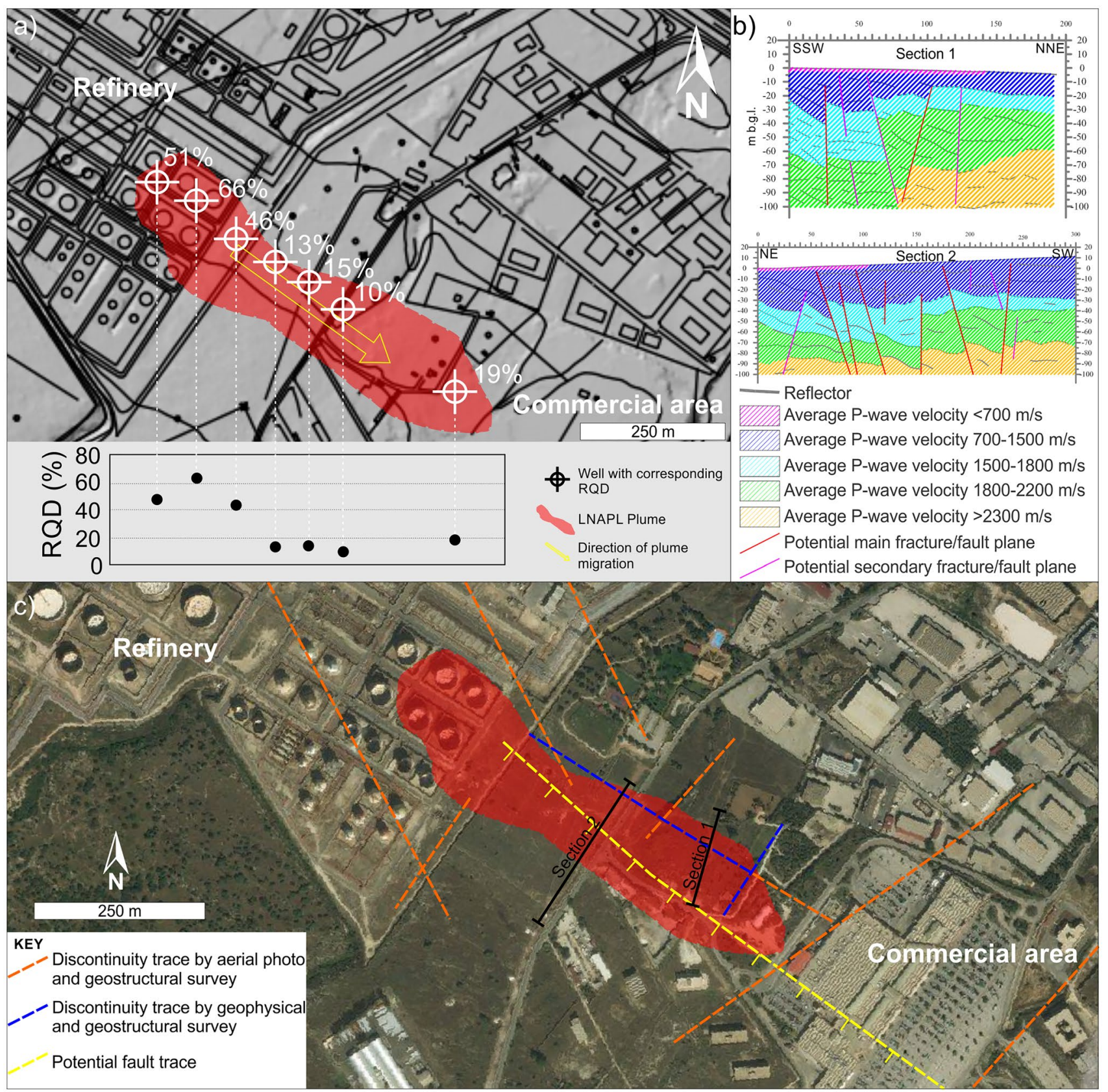

Fig. 7 a) Sketch of the LNAPL plume on a DTM of the area highlighting the decreasing RQD towards SW at the LNAPL/groundwater table interface depth; b) seismic reflection section highlighting the potential fracture/fault planes occurring in the subsoil; c) main surveyed structural sets and their spatial relationship with the LNAPL plume 
To support and verify the geophysical datum, a geostructural study allowed identifying a likely NW-SE trending fault well overlapping with the area affected by the migration of the LNAPL FP and DP plumes (Fig. 7c). The presence of such fault is also suggested by aerial photo evidences, which highlight the occurrence of hydrographic network anomalies and the presence of a scarp affecting the Monti Climiti formation. Moreover, a discontinuity system composed of NW-SE, NNW-SSE, and NE-SW trending sets was surveyed at rock masses cropping out in the study area. From the qualitative point of view, discontinuities are generally close to open, with hard (calcite) to soft filling material; a close spacing affects the NW-SE set.

The combination of the above-reported geostructural features seems affecting the permeability of the area, whose local estimated value is about one order of magnitude higher than those measured at existing piezometers in the refinery area. In fact, permeability tests carried out between the refinery and the commercial areas returned the values of hydraulic conductivity of $2 \times 10^{-4} \mathrm{~m} / \mathrm{s}$, thus supporting the hypothesis of a peculiar setting enhancing the plume migration towards SW.

\section{Discussion}

Data presented in this paper and related outcomes pave the way to multiple discussion points, with respect to both the environmental implications and the scientific aspects involved in the study (Fig. 8).
Starting from the environmental impact, the 7-year contamination monitoring showed that the pollution arising from LNAPL product accidentally leaked from a storage refinery tank needs a long-lasting monitoring and remediation even if the leakage is temporally limited. This is because the free-phase product mobility is linked not only to the groundwater flow and water table oscillation, but also to the rock mass degree of fracturing and the resulting anisotropy. This aspect gains relevance especially when the contamination affects a complex geo-hydrogeological contest, represented by a dual-porosity aquifer developed within a differently fractured carbonate rock masses, affected also by a certain degree of karstification. In fact, in such settings, the infiltration and transport of water and contaminants are favored by the presence of enhancedporosity and permeability conditions (e.g., White and White 1989; Ford and Williams 2007; Vesper et al. 2000; Fryar 2021). The point-source product migration analyzed herein proved well dependent on this aspect; in fact, a relation between the FP product thickness in wells and water table oscillation was found, with apparent thickness values reducing under groundwater level rising and vice versa. This is a typical condition of an unconfined aquifer affected by a good hydraulic conductivity and reflects the slight seasonal variations affecting the hydrogeological regime. Experimental data confirm that the permeability conditions rely on the presence of fractures within the rock mass, with highest estimated permeability value at the contaminated sector analyzed herein. These are about one order of magnitude higher than those measured at

\section{Scientific issue}

A free-phase product of light hydrocarbons, leaked from a storage tank, affected by:

anomalous migration trend, not consistent with the static groundwater flow direction of the area.

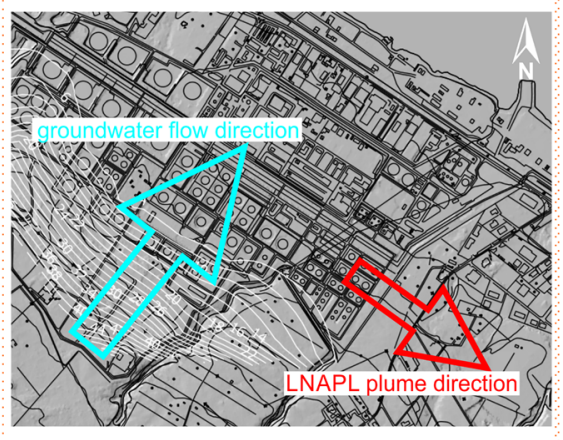

\section{Methodological approach}

1) Collection of geological and hydrogeological data from 630 wells and production of a GIS database.

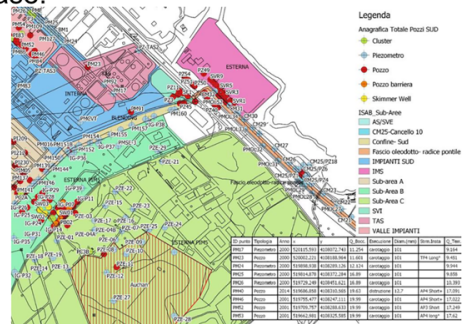

2) Analysis of plume evolution in terms of freephase apparent thickness over the 2014-2020 interval.

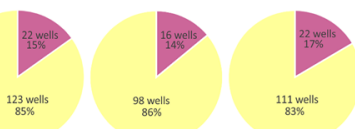

3)Analysis of factors affecting the plume migration

4) Statistical analysis of real vs apparent thickness LNAPL values.

\section{Main outcomes}

Factors involved in the plume migration:

a) Geology: rock fracturing, karst features.

b) Tectonics: presence of structural alignments in the subsoil.

c) Anthropic activity: pumping.

2014-2020 plume evolution:

a) Reduction of wells affected by product.

b) Reduction of product thickness.

Real vs apparent free-phase product thickness:

a) Positive linear statistical relation.

b) Influence of seasonal water table oscillation.

c) Empirical prediction of real thickness.

Fig. 8 Summary of the main aspects of this research and achieved outcomes 
the refinery area, thus suggesting the possible existence of groundwater preferential drainage directions. This leads the discussion theme towards a further scientific aspect involving the plume migration trend. In fact, it was observed that the LNAPL plumes, both the free-phase and the dissolved ones, migrate towards south-east, although the static groundwater flow direction is oriented towards north-east, consistently to literature data. This peculiar trend was explained herein by considering the action of three contemporaneous factors (Fig. 8), among which the anthropic groundwater exploitation activity. Nevertheless, this alone could hardly support the constant anomalous plume direction, since several pumping spots are widespread in the area. Therefore, the degree of rock fracturing was studied from drill cores, highlighting that RDQ values decrease along an hypothetical borehole transept parallel to the plume elongation. This suggests an increasing of the rock mass fracturing towards south-east, supporting the hypothesis of a more favorable product migration, under the dynamic effects of the area, towards a preferential direction. This aspect introduces a relevant consideration on how the anisotropy of fractured aquifers influences the mobility of a contamination plume, unlike what happen on porous media. It was further ascertained herein by geophysical and geostructural studies, which shed light on the underground presence of main structural sets showing a direction parallel to the one followed by the LNAPL plume, thus suggesting that tectonics plays a key role in the migration of pollutants. Such aspect gains relevance in fractured aquifers, where groundwater and eventual supernatant product move within the fracture networks, thus highlighting the importance of the underground geostructural knowledge when dealing with similar issues, or designing remediation measures. In this case, the detection of such structures brought a fundamental hint to locate the pump and treat systems aimed at intercepting the plumes migration, which is also conditioned by the presence of karst cavities acting as great discontinuities. Analyzed monitoring data show a reduction of both the number of wells holding free-phase product and its apparent thickness in the 2014-2020 time interval, thus proving the positive impact of the specific remediation measures.

It is understood that the free-phase product thickness measured in wells is not representative of the real supernatant thickness in the aquifer, which was estimated herein through baildown tests carried out at key piezometers. By comparing real thickness values and corresponding apparent ones, their statistical positive relation was outlined herein, with satisfactory results by considering the seasonal influence of the groundwater oscillation on the apparent thickness. Obtained equations represent also a tentative prediction approach to statistically predict the real product thickness starting from the knowledge of the one, more easily measured in wells. This aspect deserves further investigations due to its practical potential, which could lead to a quicker supernatant real thickness estimation especially during either preliminary site-specific studies or emergency characterization, which may suffer from low-budget and low time availabilities.

\section{Conclusions}

The LNAPL contamination affecting an industrial area of southeastern Sicily (Italy) was studied herein to analyze some peculiarities of its evolution in terms of migration path and thickness of the free-phase product. This, represented by light hydrocarbons leaked from a storage tank, showed an anomalous migration trend within the carbonate aquifer, which was not consistent with the static groundwater flow direction of the area. This issue was treated through the analysis of geological and hydrogeological data referring to numerous wells, which were used to compile a GIS database. The plume evolution was monitored from 2014 to 2020 , with respect to both the free-phase product and the dissolved contamination rate, and analyzed in the frame of the geostructural and geological setting. Furthermore, a statistical analysis of real vs apparent supernatant thickness in well was also presented to find out potential prediction equations for practical applications. Achieved results can be summarized as follows:

(1) Three main factors influence the plume migration pattern. These are the geology (i.e., presence of a variable degree of rock fracturing and karst features); tectonics (i.e., presence in the subsoil of main mechanical discontinuities, likely related to main structural alignment crossing this sector of the region); and anthropic activity (i.e., pumping from widespread spots).

(2) The 2014-2020 monitoring returned positive outcomes in terms of contamination reduction, which is reflected in a lowering of the number of wells affected by freephase product, a narrowing of the contamination plumes, and a lowering of the free-phase supernatant apparent thickness in wells.

(3) The statistical analysis carried out to find out the relation between apparent and real thicknesses of free-phase product returned satisfactory positive relations, leading to the possibility of predicting the real thickness from static well sampling. The scientific potential of this aspect deserves further investigation, as it could lead to quicker supernatant real thickness estimation especially when time-consuming practices should be avoided.

Acknowledgements The authors thank ISAB S.r.l. for having authorized the scientific publication of presented data. 
Funding Open access funding provided by Università degli Studi di Catania within the CRUI-CARE Agreement.

Open Access This article is licensed under a Creative Commons Attribution 4.0 International License, which permits use, sharing, adaptation, distribution and reproduction in any medium or format, as long as you give appropriate credit to the original author(s) and the source, provide a link to the Creative Commons licence, and indicate if changes were made. The images or other third party material in this article are included in the article's Creative Commons licence, unless indicated otherwise in a credit line to the material. If material is not included in the article's Creative Commons licence and your intended use is not permitted by statutory regulation or exceeds the permitted use, you will need to obtain permission directly from the copyright holder. To view a copy of this licence, visit http://creativecommons.org/licenses/by/4.0/.

\section{References}

Andriani GF, Parise M (2015) On the applicability of geomechanical models for carbonate rock masses interested by karst processes. Environmental Earth Sciences 74(12):7813-7821. https://doi.org/ $10.1007 / \mathrm{s} 12665-015-4596-\mathrm{z}$

ASTM E2531-06 (2014) In Standard guide for development of conceptual site models and remediation strategies for light nonaqueousphase liquids released to the subsurface. ASTM International, West Conshohocken, PA, USA

Atteia O, Palmier C, Schäfer G (2019) On the influence of groundwater table fluctuations on oil thickness in a well related to an LNAPL contaminated aquifer. J Contam Hydrol 223:103476. https://doi. org/10.1016/j.jconhyd.2019.03.008

Azimi R, Vaezihir A, Lenhard RJ, Hassanizadeh SM (2020) Evaluation of LNAPL behavior in water table inter-fluctuate zone under groundwater drawdown condition. Water 12:2337. https://doi.org/ 10.3390/w12092337

Baldi G, Pacciani M (1997) Acquiferi contaminati da idrocarburi: tecniche di quantificazione dell'inquinante. Prove in situ. Acque sotterranee, 55. Settembre 1997:21-36

Ballestero TP, Fiedler FR, Kinner NE (1994) An investigation of the relationship between actual and apparent gasoline thickness in a uniform sand aquifer. Ground Water 32:708-718. https://doi.org/ 10.1111/j.1745-6584.1994.tb00911.x

Carbone S, Lentini F (1981) Caratteri deposizionali delle vulcaniti del Miocene superiore negli Iblei (Sicilia Sud-Orientale). Geol Romana 20:79-101

Carbone S, Grasso M, Lentini F (1982) Considerazioni sull'evoluzione geodinamica della Sicilia Sud-Orientale dal Cretaceo al Quaternario. Mem Soc Geol It 24:367-386

Carbone S, Grasso M, Lentini F (1986) Carta Geologica Del Settore Nord-Orientale Ibleo. S.EL.CA., Firenze

Cassidy NJ (2007) Evaluating LNAPL contamination using GPR signal attenuation analysis and dielectric property measurements: practical implications for hydrological studies. J Contam Hydrol 94:49-75. https://doi.org/10.1016/j.jconhyd.2007.05.002

Catalano S, Romagnoli G, Tortorici G (2010) Kinematics and dynamics of the Late Quaternary rift-flank deformation in the Hyblean Plateau (SE Sicily). Tectonophysics 486:1-14. https://doi.org/10. 1016/j.tecto.2010.01.013

Chang JI, Lin CC (2006) A study of storage tank accidents. J Loss Prev Process Ind 19(1):51-59

Ching Sheng O, Ngui WK, Kar Hoou H, Meng Hee L, Leong MS (2019) Review of underground storage tank condition monitoring techniques. In: MATEC Web Conf., vol. 255

de Pastrovich TL, Barthel Y, Chiarelli A, Fussell DR (1979) Protection of groundwater from oil pollution. Concawe 3/79, Concawe, The Hague, Netherlands
Deere DU (1963) Technical description of rock cores for engineering purposes. Felsmech Ingenieurgeologie (rock Mech Eng Geol) 1(1):16-22

Deska I, Ociepa E (2013) Impact of the water table fluctuations on the apparent thickness of light non-aqueous phase liquids. Ecol Chem Eng A 20:771-778. https://doi.org/10.2428/ecea.2013.20(07)070

Dippenaar MA, Sole MD, Van Rooy JL, du Toit GJ, Reynecke JL (2005) Determining actual LNAPL plume thickness: review and case study in a fractured aquifer. Bull Eng Geol Environ 64:347360. https://doi.org/10.1007/s10064-005-0278-5

Elshall AS, Castilla-Rho J, El-Kadi AI et al (2021) Sustainability of groundwater. In: Reference module in earth systems and environmental sciences. Elsevier, p B9780128211397001000

Etkin DS (2009) 40-year analysis of US oil spillage rates. Environment Canada, Canada, p 1332

Fewtrell P, Hirst IL (1998) A review of high-cost chemical/petrochemical accidents since Flexborough 1974. Ichem E Loss Prev Bull $1: 140$

Ford D, Williams P (2007) Karst hydrogeology and geomorphology: Ford/Karst hydrogeology and geomorphology. John Wiley \& Sons Ltd, West Sussex, England

Fryar AE (2021) Groundwater of carbonate aquifers. In: Global Groundwater. Elsevier, pp 23-34

Frollini E, Petitta M (2018) Free LNAPL volume estimation by pancake model and vertical equilibrium model: comparison of results, limitations, and critical points. Geofluids. https://doi.org/10.1155/ 2018/8234167

Gailey RM (2017) Inactive supply wells as conduits for flow and contaminant migration: conditions of occurrence and suggestions for management. Hydrogeol J 25:2163-2183. https://doi.org/10.1007/ s10040-017-1588-y

Gatsios E, García-Rincón J, Rayner JL, McLaughlan RG, Davis GB (2018) LNAPL transmissivity as a remediation metric in complex sites under water table fluctuations. J Environ Manag 215:40-48. https://doi.org/10.1016/j.jenvman.2018.03.026

Grasso M, Lentini F, Lombardo G, Scamarda G (1979) Distribuzione delle facies cretaceo-mioceniche lungo l'allineamento AugustaM. Lauro (Sicilia Sud-Orientale). Boll Soc Geol It 98:175-188

Gruszczenski TS (1987) Determination of a realistic estimate of the actual formation product thickness using monitor wells: a field bailout test. In: Proc Conf on Petroleum Hydrocarbons and Organic Chemicals in Ground Water: Prevention, Detection, and Restoration, Natl Ground Water Assoc, Dublin, OH, pp 235-253

Guo XJ, Meng QS, Wang JC, Jia YG, Guo J (2007) Leakage detection of underground pressureless industrial waste water pipeline using GPR electrical and SP method. Prog Geophys 22(1):279-282

Hardisty PE, Wheater HS, Birks D, Dottridge J (2003) Characterization of LNAPL in fractured rock. Q J Eng GeolHydrogeol 36:343-354. https://doi.org/10.1144/1470-9236/03-019

Hubbard SS, Chen J, Peterson J, Majer E, Williams K, Swift DJ, Mailloux B, Rubin Y (2001) Hydrogeological characterization of the South Oyster bacterial transport site using geophysical data. Water Resour Res 37(10):2431-2456. https://doi.org/10. 1029/2001WR000279

Hughes JP, Sullivan CR, Zinner RE (1988) Two techniques for determining the true hydrocarbon thickness in an unconfined sandy aquifer. In: Proceedings of the National Water Well Association of Ground Water Scientists and Engineers and the American Petroleum Institute Conference on Petroleum Hydrocarbons and Organic Chemicals in Ground Water: Prevention, Detection and Restoration, vol. 1, pp 291-314

ITRC (Interstate Technology \& Regulatory Council) (2018) LNAPL site management: LCSM evolution, decision process, and remedial technologies. LNAPL-3. Interstate Technology \& Regulatory Council. LNAPL Update Team, Washington, D.C. https://lnapl-3. itrcweb.org. Accessed Dec 2021 
Ji S-H, Nicholl MJ, Glass RJ, Lee K-K (2006) Influence of simple fracture intersections with differing aperture on density-driven immiscible flow: wetting versus nonwetting flows: influence of intersections on immiscible flow. Water Resour Res. https://doi. org/10.1029/2006WR004953

Lari KS, King A, Rayner JL, Davis GB (2021) Quantifying the benefits of in-time and in-place responses to remediate acute LNAPL release incidents. J Environ Manage 287:112356. https://doi.org/ 10.1016/j.jenvman.2021.112356

Lenhard RJ, Rayner JL, Davis GB (2017) A practical tool for estimating subsurface LNAPL distributions and transmissivity using current and historical fluid levels in groundwater wells: effects of entrapped and residual LNAPL. J Contam Hydrol 205:1-11

Li H, Lu Q, Feng X, Liu C, Liang W, Zou L (2012) Study on the effect of LNAPL pollution to soil complex permittivity. In: 14th International Conference on Ground Penetrating Radar (GPR), pp 34-38. https://doi.org/10.1109/ICGPR.2012.6254827

Liying S, Yibo L (2010) Review of on-line defects detection technique for above ground storage tank floor monitoring. In: 2010 8th World Congress on Intelligent Control and Automation, IEEE, pp 4178-4181

Mercer JW, CP Spalding (1991) Chapter 5: Characterization of the VadoseZone. Seminar Publication: Site Characterization for Subsurface Remediation,EPA/625/4-o1/026, pp 59-71

Nelson RA (2001) Geologic analysis of naturally fractured reservoirs, 2nd edn. Gulf Professional Pub, Boston

Pedley HM (1981) Sedimentology and paleoenvironment of the southeast Sicilian Tertiary platform carbonates. Sed Geol 28:273-291

Pyrak-Nolte LJ, Myer LR, Cook NGW, Witherspoon PA (1987) Hydraulic and mechanical properties of natural fractures in lowpermeability rock. In: Herget G, Vongpaisal S (eds) Proceedings of the 6th International Congress of Rock Mechanics. Balkema, Rotterdam, pp 225-231

Schwille F (1967) Petroleum contamination of the subsoil: a hydrological problem. In: Brighton (ed) The joint problems of the oil and water industries: proceedings of a symposiumheld at the Hotel Metropole, Brighton, 18-20 January 1967. Institute of Petroleum, London, pp 23-54

Steffy DA, Johnston CD, Barry DA (1995) A field study of the vertical immiscible displacement of LNAPL associated with a fluctuating. IAHS Publ Proc Reports-Intern Assoc Hydrol Sci 225:49-60

van Dam J (1967) The migration of hydrocarbons in a water-bearing stratum. In: The joint problems of the oil and water industries: proceedings of a symposium held at the Hotel Metropole, Brighton. 18-20. Institute of Petroleum, London, pp 55-96

Vesper DJ, Loop CM, White WB (2000) Contaminant transport in karst aquifers. Theoretical and Applied Karstology 13(14):63-73

Walker RL (2001) Effects Of pumping on ground-water flow near water-supply wells in the Lower Potomac-Raritan-Magothy aquifer. Pennsauken Township, Camden County, New Jersey, p 12 (U.S. Geological Survey Water-Resources Investigations Report 00-4012)

White WB, White EL (eds) (1989) Karst hydrology: concepts from the Mammoth Cave area. Springer, US, Boston, MA

Yang Z, Niemi A, Fagerlund F, Illangasekare T (2012) Effects of single-fracture aperture statistics on entrapment, dissolution and source depletion behavior of dense non-aqueous phase liquids. J Contam Hydrol 133:1-16. https://doi.org/10.1016/j.jconhyd. 2012.03.002 